\title{
$\mathbf{J}|\mathbf{A}| \mathbf{C} \mid \mathbf{S}$ \\ COMMUNICATIONS
}

Published on Web 10/11/2002

\section{The First Chiral Organometallic Triangle for Asymmetric Catalysis}

\author{
Suk Joong Lee, Aiguo Hu, and Wenbin Lin* \\ Department of Chemistry, CB\#3290, University of North Carolina, Chapel Hill, North Carolina 27599
}

Received August 11, 2002

Coordination-driven self-assembly of inorganic and organometallic cycles and cages has witnessed tremendous growth over the past decade. ${ }^{1-5}$ Numerous metallocorners such as cis-[M(phosphine $\left.)_{2}\right]^{2+},{ }_{1}^{1}$ cis- $[\mathrm{M}(\mathrm{en})]^{2+},{ }^{3}$ fac- $(\mathrm{CO})_{3} \operatorname{ReX},{ }^{4}$ and $\mathrm{M}_{2}$ (carboxylate $)_{2}$ units ${ }^{5}$ have been utilized to construct metallosupramolecular assemblies that have not only exhibited interesting structures but also shown promises for applications in catalysis, ${ }^{6}$ chemical sensing, ${ }^{7}$ and selective inclusion of guest molecules. ${ }^{8}$ Despite the importance of asymmetric catalysis in the production of chiral compounds, ${ }^{9}$ there have been few reports on the design of chiral metallosupramolecular assemblies. ${ }^{10}$ Moreover, none of the known chiral metallosupramolecular assemblies have been explored for applications in asymmetric catalysis. We surmise that incorporation of a chiral ligand into a conformationally rigid metallosupramolecular system would lead to a well-defined enzyme-like chiral pocket or functionality, which could find applications in chiral sensing and asymmetric catalysis. Our proof of principle experiments use $1,1^{\prime}$ bi-2-naphthol (BINOL) as the key building block for the construction of functional chiral metallosupramolecular assemblies with the hope of taking advantage of the well-documented utility of its chirality for enantioselective processes. ${ }^{11} \mathrm{We}$ have recently reported a chiral molecular square that is capable of enantioselective sensing of chiral amino alcohols via fluorescence quenching. ${ }^{10 a}$ We report here the self-assembly and characterization of the first chiral organometallic triangles $\left[\text { cis- }\left(\mathrm{PEt}_{3}\right)_{2} \mathrm{Pt}\left(\mathbf{L}_{\mathbf{1 - 4}}\right)\right]_{3}$ (where $\mathbf{L}_{\mathbf{1}-\mathbf{4}}$ is enantiopure 4,4'-bis(alkynyl)-1,1'-binaphthalene) and their applications in highly enantioselective diethylzinc additions to aldehydes to afford chiral secondary alcohols. ${ }^{12}$

Enantiomerically pure atropisomeric 6,6'-dichloro-2,2'-diethoxy$1,1^{\prime}$-binaphthyl-4,4'-bis(acetylene) $\mathbf{L}_{1}$ was synthesized in two steps in $67 \%$ overall yield starting from 6,6'-dichloro-4,4'-dibromo-2,2' diethoxy-1,1'-binaphthalene which was previously reported by us (Scheme 1). ${ }^{10 a}$ Dimethoxy analogue $\mathbf{L}_{2}$ and bis(tert-butyldimethylsilyl) analogue $\mathbf{L}_{\mathbf{3}}$ were similarly prepared, while dihydroxy analogue $\mathbf{L}_{\mathbf{4}}$ was prepared in quantitative yield by treating $\mathbf{L}_{\mathbf{3}}$ with tetra( $n$-butyl)ammonium fluoride (TBAF) in THF. All of these ligands have been characterized by ${ }^{1} \mathrm{H}$ and ${ }^{13} \mathrm{C}\left\{{ }^{1} \mathrm{H}\right\}$ NMR, UVvis, circular dichroism (CD) spectroscopies, and high-resolution mass spectrometry.

Treatment of ligand $\mathbf{L}_{\mathbf{1 - 3}}$ with 1 equiv of cis- $\mathrm{Pt}\left(\mathrm{PEt}_{3}\right)_{2} \mathrm{Cl}_{2}$ in the presence of $\mathrm{CuI}$ in a mixture of diethylamine and dichloromethane at room temperature afforded chiral cycles $\mathbf{1 - 3}$ in moderate yields $(38-45 \%)$ after purification by silica gel column chromatography. Attempts to synthesize the hydroxy cycle $\mathbf{4}$ by treating $\mathbf{L}_{\mathbf{4}}$ with 1 equiv of cis- $\mathrm{Pt}\left(\mathrm{PEt}_{3}\right)_{2} \mathrm{Cl}_{2}$ have failed, presumably due to competitive coordination of the 2,2'-dihydroxy groups to the Pt centers. Instead, cycle 4 was obtained in quantitative yield by treating 3 with TBAF in THF. Compounds $\mathbf{1}-\mathbf{4}$ have been characterized by ${ }^{1} \mathrm{H},{ }^{13} \mathrm{C}\left\{{ }^{1} \mathrm{H}\right\}$,

* To whom correspondence should be addressed. E-mail: wlin@unc.edu.

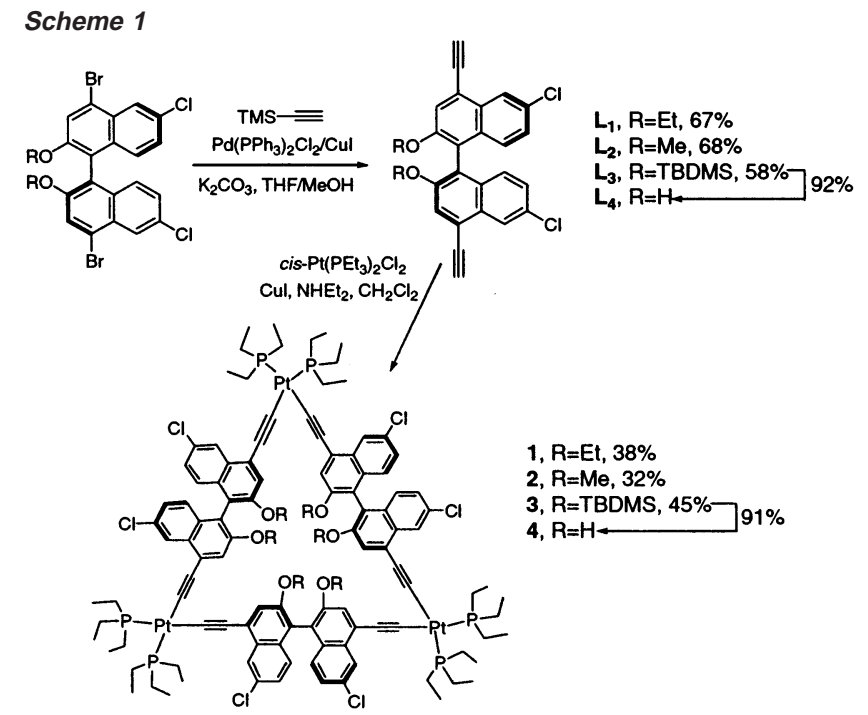

and ${ }^{31} \mathrm{P}\left\{{ }^{1} \mathrm{H}\right\}$ NMR spectroscopy, mass spectrometry, elemental analysis, and IR, UV-vis, and circular dichroism (CD) spectroscopies.

NMR data of 1-4 showed a single ligand environment, suggesting the formation of cyclic species. For example, the ${ }^{31} \mathrm{P}\left\{{ }^{1} \mathrm{H}\right\}$ NMR spectrum of 1 exhibits a single peak at $3.51 \mathrm{ppm}$ with a set of ${ }^{195} \mathrm{Pt}$ satellites $\left(J_{\mathrm{Pt}-\mathrm{P}}=2282.8 \mathrm{~Hz}\right)$. There is also only one single set of signals for the acetylenic and aromatic carbon atoms in its ${ }^{13} \mathrm{C}\left\{{ }^{1} \mathrm{H}\right\}$ NMR spectrum. The aromatic region of ${ }^{1} \mathrm{H}$ NMR spectrum of $\mathbf{1}$ is deceptively simple with only three singlets, apparently a result of accidental overlap of $\mathrm{H}_{7}$ and $\mathrm{H}_{8}$ signals. Mass spectroscopic data showed the presence of molecular ions due to trinuclear species for $\mathbf{1 - 4}$ and thus unambiguously established their cyclic trimeric nature. ${ }^{13}$ The $v(\mathrm{C} \equiv \mathrm{C}-\mathrm{H})$ stretches at $\sim 3280 \mathrm{~cm}^{-1}$ in $\mathbf{L}_{1-4}$ disappeared upon the formation of $\mathbf{1 - 4}$, and the IR spectra of $\mathbf{1 - 4}$ exhibit expected $v(\mathrm{C} \equiv \mathrm{C})$ stretches at $\sim 2100 \mathrm{~cm}^{-1}$. The formulations of 1-4 are also supported by microanalysis results. All of these spectroscopic data are consistent with a cyclic trinuclear structure with approximate $D_{3}$ symmetry for $\mathbf{1 - 4}$. Numerous attempts have however failed to produce $\mathrm{X}$-ray diffraction quality single crystals of $\mathbf{1 - 4}$.

The electronic spectra of $\mathbf{L}_{\mathbf{1}-\mathbf{4}}$ show three major $\pi \rightarrow \pi^{*}$ transitions at $\sim 240, \sim 300$, and $\sim 357 \mathrm{~nm}$. While the absorption at $\sim 240 \mathrm{~nm}$ is due to the naphthyl $\pi \rightarrow \pi^{*}$ transition, the absorptions at $\sim 300$ and $\sim 357 \mathrm{~nm}$ are probably due to acetylenic $\pi \rightarrow \pi^{*}$ transitions that have been delocalized into naphthyl ring systems. Upon the formation of metallocycles $\mathbf{1 - 4}$, the absorption at $\sim 240$ $\mathrm{nm}$ of $\mathbf{L}_{\mathbf{1 - 4}}$ remains unshifted, while the lower energy transitions of $\mathbf{L}_{\mathbf{1 - 4}}$ have red-shifted by more than $15 \mathrm{~nm}$. Such bathochromic shifts have been well-established in platinum acetylides, owing to the mixing of Pt p-orbitals into the acetylenic $\pi \rightarrow \pi^{*}$ bands. ${ }^{14} \mathrm{~A}$ new band also appeared at $\sim 202 \mathrm{~nm}$, probably due to the cis-Pt- 


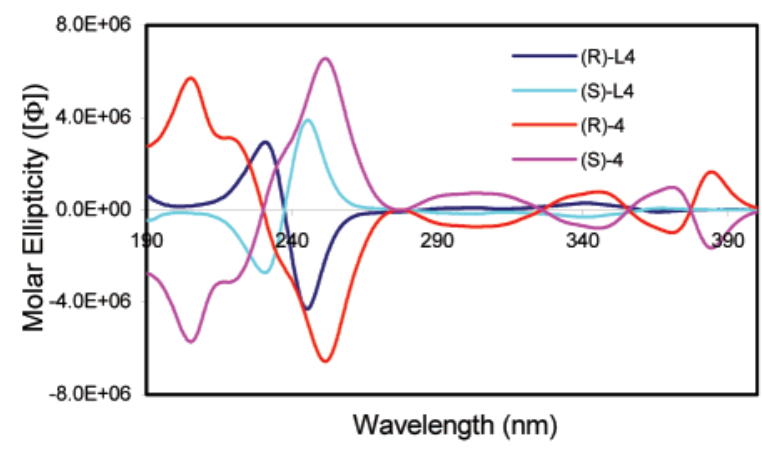

Figure 1. CD spectra of $\mathbf{L}_{\mathbf{4}}$ and $\mathbf{4}$ in acetonitrile.

Table 1. Diethylzinc Additions to Aldehydes Catalyzed by Ti(IV) Complexes of $\mathbf{4}^{\mathrm{a}}$

\begin{tabular}{|c|c|c|c|c|}
\hline Entry & Aldehyde & Temp & Conversion $^{b}$ & e.e. $(\%)^{c}$ \\
\hline 1 & & $\mathrm{rt}$ & $>95 \%$ & 91 \\
\hline \multirow{2}{*}{2} & & $\mathrm{rt}$ & $>95 \%$ & 91 \\
\hline & & $0^{\circ} \mathrm{C}$ & $>95 \%$ & 92 \\
\hline 3 & & $\mathrm{rt}$ & $>95 \%$ & 90 \\
\hline 4 & & $\mathrm{rt}$ & $>95 \%$ & 91 \\
\hline 5 & & $\mathrm{rt}$ & $>95 \%$ & 89 \\
\hline 6 & & $\mathrm{rt}$ & $>95 \%$ & 90 \\
\hline
\end{tabular}

${ }^{a}$ All reactions were carried out with 7 equiv of $\mathrm{Ti}\left(\mathrm{O}^{i} \mathrm{Pr}\right)_{4}$ (on the basis of $\left.\mathbf{L}_{4}\right) .{ }^{b}$ Conversion was determined by ${ }^{1} \mathrm{H}$ NMR. ${ }^{c}$ ee's were determined using a Chiracel-OD HPLC column except for $p$-tolualdehyde (OJ column).

$\left(\mathrm{PEt}_{3}\right)_{2}$ moieties. CD spectra of ligands $\mathbf{L}_{\mathbf{1}-\mathbf{4}}$ exhibit one major bisignate band corresponding to naphthyl $\pi \rightarrow \pi^{*}$ transitions and two minor bands due to the other two lower energy $\pi \rightarrow \pi^{*}$ transitions (Figure 1). CD spectra of 1-4 exhibited these three bands similar to $\mathbf{L}_{\mathbf{1 - 4}}$, but with red-shifts in energy and higher intensities. Interestingly, a new intense CD band appeared at $\sim 202 \mathrm{~nm}$, assignable to the transitions associated with $c i s-\mathrm{Pt}\left(\mathrm{PEt}_{3}\right)_{2}$ moieties. This result suggests that triethylphosphines on the Pt centers adopt a propeller-type arrangement (relative to the naphthyl groups), apparently steered by chiral binaphthyl moieties. ${ }^{15}$ Enhanced lower energy CD signals for $\mathbf{1 - 4}$ are consistent with the presence of multiple ligands in each metallocycle, while their similarity with those of $\mathbf{L}_{\mathbf{1 - 4}}$ indicates that the dihedral angles between naphthyl rings in $\mathbf{1 - 4}$ are quite similar to those of $\mathbf{L}_{\mathbf{1 - 4}}$.

$$
\underset{A r}{\stackrel{O}{\mathrm{l}_{H}}}+\mathrm{Et}_{2} \mathrm{Zn} \frac{(S)-4}{\mathrm{Ti}_{\left(\mathrm{O}^{\prime} \mathrm{Pr}\right)_{4}}} \stackrel{\mathrm{HO}}{\mathrm{Ar}_{\mathrm{Et}}}
$$

With dihydroxyl groups present in $\mathbf{4}$, we expect it to be applicable in asymmetric catalysis. We have thus carried out prototypical diethylzinc additions to aromatic aldehydes using a combination of 4 and $\operatorname{Ti}\left(\mathrm{O}^{i} \mathrm{Pr}\right)_{4}$ (eq 1). ${ }^{16}$ As shown in Table 1, the $\mathrm{Ti}(\mathrm{IV})$ complexes of $\mathbf{4}$ are excellent catalysts for the additions of diethylzinc to aromatic aldehydes to generate chiral secondary alcohols in very high selectivity, yield, and enantioselectivity. In comparison, when free ligand $\mathbf{L}_{\mathbf{4}}$ was used instead of $\mathbf{4}$, a lower ee $(80 \%)$ was obtained for the addition of diethylzinc to 1-naphthaldehyde. The broad substrate scope for catalytic diethylzinc additions using 4 and $\operatorname{Ti}\left(\mathrm{O}^{i} \mathrm{Pr}\right)_{4}$ suggests that there is significant flexibility in the dihydroxy groups to accommodate aldehydes of various sizes. This result is entirely consistent with the $\mathrm{CD}$ data.

In summary, a family of chiral organometallic triangles has been readily assembled on the basis of robust Pt-acetylide linkage. Metallocycle $\mathbf{4}$ has been used for highly enantioselective catalytic diethylzinc additions to aromatic aldehydes.

Acknowledgment. We thank NSF (CHE-0208930) for financial support. W.L. is an A. P. Sloan Fellow, a Beckman Young Investigator, a Cottrell Scholar of Research Corp., and a Camille Dreyfus Teacher-Scholar.

Supporting Information Available: Experimental procedures, analytical data, and seven figures (PDF). This material is available free of charge via the Internet at http://pubs.acs.org.

\section{References}

(1) (a) Stang, P. J.; Olenyuk, B. Acc. Chem. Res. 1997, 30, 502. (b) Leininger, S.; Olenyuk, B.; Stang, P. J. Chem. Rev. 2000, 100, 853-907.

(2) (a) Holiday, B. J.; Mirkin, C. A. Angew. Chem., Int. Ed. 2001, 40, $2022-$ 2043. (b) Klausmeyer, K. K.; Rauchfuss, T. B.; Wilson, S. R. Angew. Chem., Int. Ed. 1998, 37, 1694-1696. (c) Lehn, J.-M. Supramolecular Chemistry, Concepts, and Perspectives; VCH: New York, 1995. (d) Laskoski, M.; Steffen, W.; Morton, J. G. M.; Smith, M. D.; Bunz, U. H. F. Angew. Chem., Int. Ed. 2002, 41, 2378.

(3) Fujita, M. Chem. Soc. Rev. 1998, 27, 417-425.

(4) (a) Dinolfo, P. H.; Hupp, J. T. Chem. Mater. 2001, 13, 3113. (b) Benlanger, S.; Hupp, J. T.; Guzei, I. A.; Rheingold, A. L. Coord. Chem. Rev. 1998 , $171,221$.

(5) Cotton, F. A.; Lin, C.; Murillo, C. A. Acc. Chem. Res. 2001, 34, 759.

(6) Merlau, M. L.; del Pilar Mejia, M.; Nguyen, S. T.; Hupp, J. T. Angew. Chem., Int. Ed. 2001, 113, 4369-4372.

(7) Lahav, M.; Gabai, R.; Shipway, A. N.; Willner, I. Chem. Commun. 1999, 1937.

(8) (a) Yoshizawa, M.; Kusukawa, T.; Fujita, M.; Yamaguchi, K. J. Am. Chem Soc. 2000, 122, 6311. (b) Yoshizawa, M.; Kusukawa, T.; Fujita, M.; Sakamoto, S.; Yamaguchi, K. J. Am. Chem. Soc. 2001, 123, 10454. (c) Lees, A. J.; Sun, S. J. Am. Chem. Soc. 2000, 122, 8956-8967.

(9) (a) Knowles, W. S. Angew. Chem., Int. Ed. 2002, 41, 1998. (b) Sharpless, K. B. Angew. Chem., Int. Ed. 2002, 41, 2024.

(10) (a) Lee, S. J.; Lin, W. J. Am. Chem. Soc. 2002, 124, 4554. (b) Olenyuk, B.; Whiteford, J. A.; Stang, P. J. Am. Chem. Soc. 1996, 118, 8221. (c) Stang, P. J.; Olenyuk, B. Angew. Chem., Int. Ed. Engl. 1996, 35, 732736. (d) Zhang, Y.; Wang, S.; Enright, G. D.; Breeze, S. R. J. Am. Chem Soc. 1998, 120, 9398-9399. (e) Shafer, L. L.; Tilley, T. D. J. Am. Chem. Soc. 2001, 123, 2683-2684.

(11) (a) Pu, L. Chem. Rev. 1998, 98, 2405. (b) Hayashi, T.; Tomioka, K Yonemitsu, O. Asymmetric Synthesis: Graphical Abstracts and Experimental Methods; Gordon and Beach Science Publishers: Amsterdam, Netherlands, 1998. (c) Noyori, R. Angew. Chem., Int. Ed. 2002, 41, 2008.

(12) Pt-alkynyl bonds have been used to construct achiral metallocycles. See: ALQaisi, S. M.; Galat, K. J.; Chai, M.; Ray, D. G., III; Rinaldi, P. L.; Tessier, C. A.; Youngs, W. J. J. Am. Chem. Soc. 1998, 120, 12149.

(13) Several molecular triangles have been constructed using approximately $90^{\circ}$ metallocorners and linear spacers. See, for example: (a) Schweiger, M.; Seidel, S. R.; Arif, A. M.; Stang, P. J. Angew. Chem., Int. Ed. 2001 40, 3467. (b) Whang, D.; Park, K.-M.; Heo, J.; Ashton, P.; Kim, K. J. Am. Chem. Soc. 1998, 120, 4899. (c) Cotton, F. A.; Daniels, L. M.; Lin, C.; Murillo, C. A. J. Am. Chem. Soc. 1999, 121, 4538.

(14) (a) Yam, V. W.-W. Acc. Chem. Res. 2002, 35, 555. (b) Manna, J.; John, K. D.; Hopkins, M. D. Adv. Organomet. Chem. 1995, 38, 79.

(15) Such a chiral propeller-type arrangement of triethylphosphines has been observed in a single-crystal structure of a related metallacyclophane built from 3,3'-dialkynyl-1,1'-binaphthyl. Unpublished results.

(16) (a) Pu, L.; Yu, H.-B. Chem. Rev. 2001, 101, 757. (b) Mori, M.; Nakai, T. Tetrahedron Lett. 1997, 38, 6233.

JA028099S 